\title{
Study on Vocabulary Teaching of TCFL from the Perspective of Characters' Pronunciation, Shape and Meaning
}

\author{
Hongli Ge \\ Faculty of Liberal Arts \\ Northwest University \\ China, 710127
}

\begin{abstract}
It is a new way for vocabulary teaching of TCFL with the help of Chinese characters' pronunciation, shape and meaning on the basis of inheriting the traditional semantics, which adapt to Chinese characteristics. We can start vocabulary teaching from Chinese characters' pronunciation. It would solve the problem of "Parallel word" in Chinese. We can solve some mistakes of similar vocabulary from the perspective of pronunciations. We also can clarify the extension of the meaning of a word from the perspective of meaning of words. We can also proceed from two aspects, such as characters' pronunciation and meaning. It would deepen vocabulary teaching. Then, we can better master Chinese.
\end{abstract}

Keywords-character pronunciation; character shape; character meaning; TCFL; vocabulary teaching

\section{INTRODUCTION}

In Chinese international education, "character standard" theory has proved that Chinese characters are an indispensable element in Chinese teaching. Chinese is different from other languages using pinyin. For more than three thousand years, at the beginning of the creation of Chinese characters, they have left their own unique print. And they have the influence on the language elements such as pronunciation, vocabulary and grammar. As we talk about Chinese, we have to mention Chinese characters. And it is an important factor. However, when we teach the vocabulary recorded by Chinese characters, we should combine with all aspects of Chinese character pronunciation, shape and meaning. By doing half the work, we will get double the result. And it would explore a unique teaching method that is truly suitable for international education in Chinese. Viewing from the HSK dynamic composition corpus, in the intermediate and advanced stages, we still make mistakes of some simple words such as "hundred" and "half" that aren't difficult to write. For example, "They also can't guarantee the emotion will be unforgettable when a child grows up and finds another partner." The author can accurately use the idiom of "unforgettable" and writes it correct. He or she would make mistakes of the character "half". And it lacks the understanding of character pronunciation, shape and meaning of the word. The Chinese critical interpretation of ancient texts is actually a subject that studies lexical semantics. Nowadays, when teaching Chinese as a foreign language, we may refer to the related theories of traditional critical interpretation of ancient texts. And then, we would explore a unique path suitable for Chinese teaching. The critical interpretation of ancient texts went to the peak in Qing dynasty, which can't be separated from the guiding ideology of the authority of critical interpretation of ancient texts at that time. That is to pursue the combination of character pronunciation, shape and meaning. Even, it pursues the combination of six concepts. 1 In international teaching of Chinese, we can make good use of this theory in vocabulary teaching.

\section{THE ROLE OF CHARACTER SHAPE IN VOCABULARY TEACHING OF TCFL}

\section{A. The Importance of Chinese Characters in the Development of Chinese}

The three elements of phonetics, vocabulary and grammar in Chinese characters and languages interact with each other. And then, they have formed the present form of modern Chinese, which is a fundamental feature that distinguishes Chinese from other languages. In Chinese, Chinese characters are the symbols to record the language The important factors affect the language. Vocabulary teaching must emphasize the glyph, pronunciation and meaning of Chinese characters. For example, one of the most obvious grammatical features of Chinese is that word order and function words would work without word-formation Most words in Chinese are made up of roots. And few words are derived from root and affixes. This characteristic of Chinese vocabulary is related to the semantic features of Chinese characters. In ancient Chinese, there is so-called "four tones of Chinese phonetics with alternative meaning".

[Qing] Duan Yucai. "Yangtze Tribune - prologue": "primary school, character shape, pronunciation, and meaning. And if we make the combination of three concepts, we would know the other two concepts from one concept. And there are ancient character shapes, current character shapes, ancient character pronunciation, current character pronunciation, ancient character meanings and current character meanings. If we make the combination of these six concepts, we would know the other five concepts from the one concept." 
Such as "磨" and "扇", when reading flat sounds, they are verbs. However, when reading falling tone, they are nouns. In the terms of writing, the Chinese characters can't directly reflect the change of tone. And they would add the affix "子" to make the distinction. For example, we could add the affix "子", it would become a noun "扇子". Also, "盖子", "起子" could be explained with similar mean. However, Chinese did not go along with this way of derivation, such as "扇子", "起 子", "盖子". On the one hand, due to this compensatory mechanism of Chinese tone (four tones of Chinese phonetics with alternative meaning), the ability of the Chinese affixes such as "子", "头", "儿" to derive new words is weak. ${ }^{2}$ On the other hand, in the terms of writing, Chinese characters, especially that phonogram, have also played a significant role, such as "益". The oracle bone ${ }^{\prime \prime}$ refers to the water overflowing from the vessel. Later, the word can also indicate the benefits, etc. We could divide these two meanings from the glyph of Chinese character. However, there is no change in pronunciation. The "益" indicates "benefits", and we could still write it as "益". And the word " 溢" indicates the water overflowing from the vessel. With the transformation of an ancient style of calligraphy in the Han Dynasty into regular script, the first part of "益" can't be directly seen as water. It adds the affix " $\% "$ to express the meaning of the image. And people can see this point from the unearthed physical characters clearly. For example, we could see it from unearthed bamboo scripts in Han dynasty. And most of phonogram is created on the basis of original character shape. And then, it would form Chinese character composed of two or more single characters. Even in the Eastern Han dynasty, many of the phonograms we are now familiar with have not yet been produced. In modern Chinese characters, the proportion of phonogram is as high as $90 \%$. This proportion is gradually increased to this quantity on the basis of insisting on expression. In the development of language as society progresses, Chinese characters have changed along with the changes of language elements (such as "the four tones of Chinese phonetics with alternative mean" and word-formation of stem and affix). And even, it would replace the changes of language elements to share the functions of language. And we can use this point to explain the phenomenon of "separation of classical style of writing and writings in the vernacular" in China. With the intervention of Chinese characters, there is a clear difference between written language and oral language. For a period of one or two thousand years, the literati can maintain the idea of "the essay of Qin and Han dynasties is the best". There is a relationship between the practice of aligning the prose in the pre-Qin dynasty and the special role of Chinese characters in Chinese.

This may be related to the inherent deficiency of Chinese affixes, such as the so-called prefix prefixes in Chinese of "有", "夏", "其" "言", " 于", "薄" and others. And the characteristic of word is generally fixed. However, they have no meaning. What's more, it may be produced for the phonological needs. And the twists and turns in the English language for grammatical needs are very different. Suffix such as "头" in 砖头(bricks), 石头(stones), 木头(wood), did not change the inflection or increase any meaning. It mostly has the phenomenon with disyllabic trend of monosyllabic syllables. And it is similar to the situation of prefix.

\section{B. The Value of Shape Interpretation in the Vocabulary Teaching of TCFL and Announcements}

Therefore, in the vocabulary teaching of Chinese as a foreign language, the glyphs are a part we can't ignore. As we mentioned before, "百" in the HSK dynamic composition corpus appeared 113 times, and the error frequency was as high as 37 times. And mostly, the mistakes of "百" are related to "白". For example, "百姓" and "百货" would be mistakenly written as "白姓" and "白货". After expanding the search range, we can find that "百" and "白" is usually misused. For example, "明白" and "白头偕老" would be mistakenly written as "明百" and "百头偕老". The word "百" is a Chinese character composed of two or more single characters. And the symbol is "一" and "白". The note is that when the quantity is one hundred, we can tell people. So, the symbols are "一" and "白". Traditionally, Chinese people can't tell the age to other people when they are one hundred years old. There is a concept of "positive and negative training" in explanations of words in ancient books. Therefore, we can believe that we can't tell the quantity of one hundred to other people. When Chinese people think the quantity is great, they would use hundred to make the expression. For example, "the Book of Family Names" refers to the Chinese surnames. Later, ordinary people will be called "百姓". There are many goods in the store. People would call it department store. There are many disadvantages and no benefits. People would call it "a hundred harm". If we can explain this term clearly, we can avoid the mistakes of "白姓" and "白货". In addition, in the long history of Chinese characters, some shapes have been changed. We should point out this phenomenon as much as possible, such as "水"(water), "手"(hand), "玉 "(jade). ${ }^{3}$ We can't deny that we can't find the word-formation of many Chinese characters. And many characters have been changed in the shapes. In the terms of vocabulary teaching, we should avoid the excessive contact with the lack of wordformation. In addition, we also need to pay attention to one thing. When we explain the meaning of the character with the shapes, we must pay attention the meaning rather than the shape memory, such as "春"(spring). In "Shuo Wen Jie $\mathrm{Zi}$ ", the word-formation is from "草" and "日". And it is phonogram ( 粪). However, we only can see "日" of the current shape. This form of illustration can't be helpful to memorize the shape. Also, it would increase the difficulty. To realize the pictograph and phonetic symbols of the word helps us to understand the meaning of the word and its extended sequence. For example, "春" refers to the growth of vegetation. The warmer of spring refers to the joy of human feelings ("满面春色"). It also refers to the kind of ignorant feelings of the girl loving the boy ("少女怀春").

\footnotetext{
Always, we would write "シ " or "兴" as a radical on one side of a character (as the upper part of "益") or "水" (for example, the lower part of "泰"). In addition, "川" is actually a character with the shape of "水". And "净", "准", "减", "凄", "凑" are characters with the shape of "水".
} 


\section{THE ROLE OF CHARACTER PRONUNCIATION IN VOCABULARY TEACHING OF TCFL}

We could explore the meaning of the word from the character pronunciation. It should be separated from the constraints of character shape. In the language, especially in the spoken word, the changes and extension of the meaning is linked with character pronunciation. When using Chinese characters to record dialects, it is important to record the pronunciation of the word sometimes. It is possible to have different records of the same word. In Wang Li's opinion, the so-called "parallel words" have different phonetic forms of the same word. And "parallel words" demonstrate this feature of Chinese. For example, the word "哈" of bowing with a great show of respect is similar to "下". "下" belongs to the artificial stocking. The initial consonant of the word is [h], [x] and [6] in the dialects [such as Changzhou, Wenzhou, Xiamen, Fuzhou and Shaanxi]. Shaanxi dialect read "下来" like [xA] [lai]. The "哈腰" firstly appeared in Dao-guang period of Qing dynasty. In addition, western Shandong dialect called it like [cia] [iau]. The dialect word is "点头下腰". This point is not widely used in vocabulary teaching in TCFL. However, it is a normal state that the dialect words become mandarin. And the development of Chinese dialects is unbalanced in dialect areas. We should have the awareness of interpreting the meaning from the character pronunciation.

\section{THE ROLE OF CHARACTER MEANING IN VOCABULARY TEACHING OF TCFL}

It should carry out the vocabulary teaching of TCFL from character meaning. And we must sort out the development of Chinese characters. For example, "班" is a Chinese character composed of two or more single characters. "王" and "王" on the left and right are variations of "玉". "J" is a variation of " 刀". It means that we can cut the jade with a knife. "班" has the meaning of distinction. In fact, the primary class and intermediate class can be used to distinguish the results of students (based on the degree of learning). Shuttle bus is to distinguish cars after a fixed period of time. On the basis of the ability, work is to distinguish the workers. Therefore, we could distinguish the duties. From the HSK dynamic composition corpus, many students would write "上班", "值班 " as "上办" and "值办". And they don't understand the meaning of the word. Therefore, it caused the results. However, the development and changes of the meaning of Chinese characters are not clear. For example, foreign students often write "安装" as "按装". The development of the meaning of "安装, 设置" is not clear. And now, we can only emphasize the difference between the two pronunciations to make a distinction. Therefore, the vocabulary teaching of TCFL ultimately depends on the study of Chinese ontology. When we completely outline the complete history of the development and changes of Chinese, the vocabulary teaching of TCFL can be developed.

\section{CONCLUSION}

In addition, we can also combine the two concepts. For example, we can combine the pronunciation with meaning. Then, we could explore the meaning of the word. For example, when we read "娘" with the original tone, it refers to the father's sisters. And now, this meaning is only used in the north dialect. When we read "娘" softly, it refers to the unmarried young woman. This name can be seen from the meaning of "姑" and "娘". In "Explanation of family relation in Erya": "The wife would call the husband's father uncle, and call the mother of the husband aunt. If the husband's parents are live, the wife would call them uncle and aunt. Otherwise, the wife would call them departed uncle and aunt. Until the Tang dynasty, the wife would call the husband's parents "uncle and aunt". In the poem "Nearby the Test": "Last night, the couple would blow out the candle, and they would Bow down to their parents." And the wife would call the husband's sister sister-in-law. In "the Peacock Flies to the Southeast", the sister would stand by the bed. The sister is the daughter of the husband's parents. Also, we would call the father's sisters "姑娘". And "娘" is the name of the mother is northern dialects. It refers to the relationship between the couple is close. Nandu in Song dynasty, also has an impact on the language. "妈" is the name of the mother is the name of the mother (people in Hangzhou still call the mother "姆妈 "). And it has replaced the original "娘"4. And now, "娘" become a dialect word. "姑妈" also replaced the "姑娘". However, "姑娘" has not been eliminated. And it refers to the daughter of next generation of the family. That is his own daughter. There are other examples of this concept in China. After the Chinese people have the next generation, they often lower their seniority and use the same name as the next generation. For example, they would call the parents grandpa and grandma like the children. 5 And then, it wouldn't be strange that to call the daughter with the name of "姑娘". After all, they are two generations of adjacent daughters of one family. Since we used the name of "姑娘" to call the daughter, and the little sister also be upgraded to "姑奶奶". Especially, the girls refer to the unmarried young woman, which also implies good wishes. The Chinese people have the tradition of "There are three forms of unfilial conduct, of which the worst is to have no descendants". One of the "Seven Outs" is that the husband can be allowed to divorce his wife without having the children. For the woman who is asked to be faithful to the husband untill death in the feudal society, it is indeed a matter of vital importance to have a son. Actually, "姑" is the husband's mother-in-law. Also, we call unmarried woman "姑". In fact, people hope the latter will be able to give birth to a son, and to be a mother-in-law. And they would be "姑". This is also a good explanation why the married woman can't be called "姑娘". If the married woman only has a daughter, she is flattered to be someone's mother-in-law in the future by someone else, and it would be a blatant ridicule. From the perspective of character pronunciation, the two meanings of "the name of the sisters of the father" and "the name of the unmarried young woman"

In the history, we only have two cases of "妈" in the literature before the Song dynasty. And one was found in "Jade articles". The other was used for the names. In the Song dynasty, there were 71 cases. In "Hexateuch", the dialects are usually similar. And even, they have many pronunciations. They are the same word. ...., In Huainan areas, it has the names of "妈", "姐", "劮". ”

It is generally used behind. That is to say, people wouldn't call the names face to face. 
should have been used in parallel time. In order to make a distinction, we read one with the original tune, and we read one softly.

In the long-term historical development of Chinese, a lot of changes have taken place in character pronunciation, shape and meanings. When we use the pronunciation, shape and meaning of words to carry out the vocabulary teaching of TCFL, we must follow the principle of "knowing what you know is the beginning of wisdom". And then, we also should avoid excessive contact or excessive emphasis on the role of Chinese characters. In addition, there are a large number of phoneticized foreign words (such as "秀" in talk shows, "bye bye", etc.) and phonetic dialects (such as "蓝瘦, 香菇" produced in 2016, and they mainly are used to express the sadness.) Also, vocabulary teaching has brought new challenges.

\section{REFERENCES}

[1] [Qing] Duan Yucai. Annotation on Shuowen Jiezi [Z]. Shanghai: Shanghai Ancient Books Publishing House, 1981.

[2] Wang Li. History of Chinese Language [z]. Beijing: Zhonghua Book Company, 2004.

[3] "Thirteen Classics Explanatory Notes and Commentaries" [Z] Beijing: Zhonghua Book Company, 1980.

[4] "Chinese Dictionary" [M]. Shanghai: Chinese Dictionary Publishing House, 1993.

[5] HSK dynamic composition corpus. http: //202.112.195.192:8060/hsk/index.a

[6] "Complete Poetry of the Tang" [Z]. Beijing: Zhonghua Book Company, 1999.

[7] "New introduction of Juyan area — Jia Qu official" [Z]. Beijing: Zhonghua Book Company, 1994.

[8] Xu Tongqiang. Research on "character standard" and language [J]. Language Teaching and Linguistic Studies, 2005, (6). 